Article

\title{
Qualitative and Quantitative Analysis of $C$-glycosyl-flavones of Iris lactea Leaves by Liquid Chromatography/Tandem Mass Spectrometry
}

\author{
Dan Chen ${ }^{1}$, Yu Meng ${ }^{1}$, Yan Zhu ${ }^{1}$, Gang Wu ${ }^{1}$, Jun Yuan ${ }^{2}$, Minjian Qin ${ }^{1, *}$ and Guoyong Xie ${ }^{1, *}$ \\ 1 Department of Resources Science of Traditional Chinese Medicines, School of Traditional Chinese Pharmacy, \\ China Pharmaceutical University, \#24 Tongjiaxiang, Gulou District, Nanjing 210009, China; \\ 1721020319@stu.cpu.edu.cn (D.C.); mengyu19900616@163.com (Y.M.); cpuzy@126.com (Y.Z.); \\ woosmail@163.com (G.W.) \\ 2 Jiangsu Key Laboratory of Regional Resource Exploitation and Medicinal Research, Huaiyin Institute of \\ Technology, Huai'an 223003, Jiangsu, China; yuanjun1109@126.com \\ * Correspondence: qmj@cpu.edu.cn (M.Q.); 1020142423@cpu.edu.cn (G.X.); \\ Tel.: +86-(0)25-8618-5130 (M.Q. \& G.X.)
}

Received: 23 October 2018; Accepted: 14 December 2018; Published: 18 December 2018

\begin{abstract}
Iris lactea Pall. var. chinensis (Fisch.) Koidz. is a traditional medicinal plant resource. To make full use of the I. lactea plant resources, constituents of I. lactea leaves were determined by high performance liquid chromatography (HPLC)-quadrupole time-of-flight tandem mass spectrometry and $22 \mathrm{C}$-glycosylflavones were identified or tentatively identified. Optimal extraction of I. lactea leaves was established via single factor investigations combined with response surface methodology. Then, HPLC coupled with a diode array detector was used to quantitatively analyze the six main components of 14 batches of I. lactea leaves grown in different areas. The results showed the $C$-glycosylflavones were the main components of I. lactea leaves, and the total contents of detected components were relatively stable for the majority of samples. These results provide a foundation for the development and utilization of I. lactea leaves.
\end{abstract}

Keywords: Iris lactea Pall. var. chinensis (Fisch.) Koidz.; HPLC-Q-TOF-MS/MS; qualitative analysis; quantitative analysis; $C$-glycosylflavone

\section{Introduction}

Iris lactea Pall. var. chinensis (Fisch.) Koidz. is a perennial herb of the Iridaceae family. This plant is widely distributed in China and was first recorded in Shen Nong's Herbal Classic. The seeds, flowers and roots are used as a folk medicine for the treatment of jaundice, pharyngitis, hemorrhoids, ulcer, vomiting blood and stranguria with turbid discharge, and the leaves are used to treat pharyngitis and joint pain of the lower back and legs [1]. Modern research has shown that I. lactea contains flavonoids, benzoquinones, stilbenes and volatiles, and possesses various bioactivities, including anti-inflammatory, antioxidant, anti-tumor, and anti-radiation effects [2-9]. In particular, irisquinone which is isolated from I. lactea seeds, has been successfully used for lung cancer, esophageal cancer, head and neck cancer as an antineoplastic agent and radiosensitizer [10]. In recent years, research on the composition and bioactivity of I. lactea has concentrated on the seeds and rhizomes, but seldom on its leaves.

Leaves are the main part of I. lactea, representing abundant biomass, and aside from their medicinal value, they are also a type of pasture in the absence of winter forage [11,12]. In our previous studies, a series of $C$-glycosylflavones which possessed anti-inflammatory and cytotoxicity activities were 
isolated from I. lactea leaves [11,13]. The activities are beneficial for people and animals, and meet the requirements of the development and utilization of these medicinal plant resources.

High performance liquid chromatography (HPLC) equipped with quadrupole time-of-flight tandem mass spectrometry (Q-TOF-MS/MS) has become an essential analytical tool in the modernization of Traditional Chinese Medicine. The method is efficient and rapid at determining the molecular weight and characteristic fragment ions, by which the structure of compounds can be identified quickly [14-17]. In the study, we used HPLC-Q-TOF-MS/MS to systematically separate and identify the compounds in I. lactea leaf extracts. Subsequently, HPLC coupled with a diode array detector (HPLC-DAD) was used for quantitative analysis of six main components of I. lactea leaves from different growing areas. This study provides a valid approach to the comprehensive quality-evaluation and better utilization of I. lactea leaves.

\section{Results and Discussion}

\subsection{Compound Identifications}

The chromatograms and total ion chromatograms of standards and samples of I. lactea are displayed in Figure 1 and each peak in chromatograms is numbered with a number corresponding to the compound information listed in Table 1. Twenty-two chemical constituents were identified or tentatively identified from I. lactea leaves based on their retention time, maximum UV absorption, mass spectum and relevant literature [11,18-25]. The chemical structures of the compounds are shown in Figure S1 (Supplementary Material).
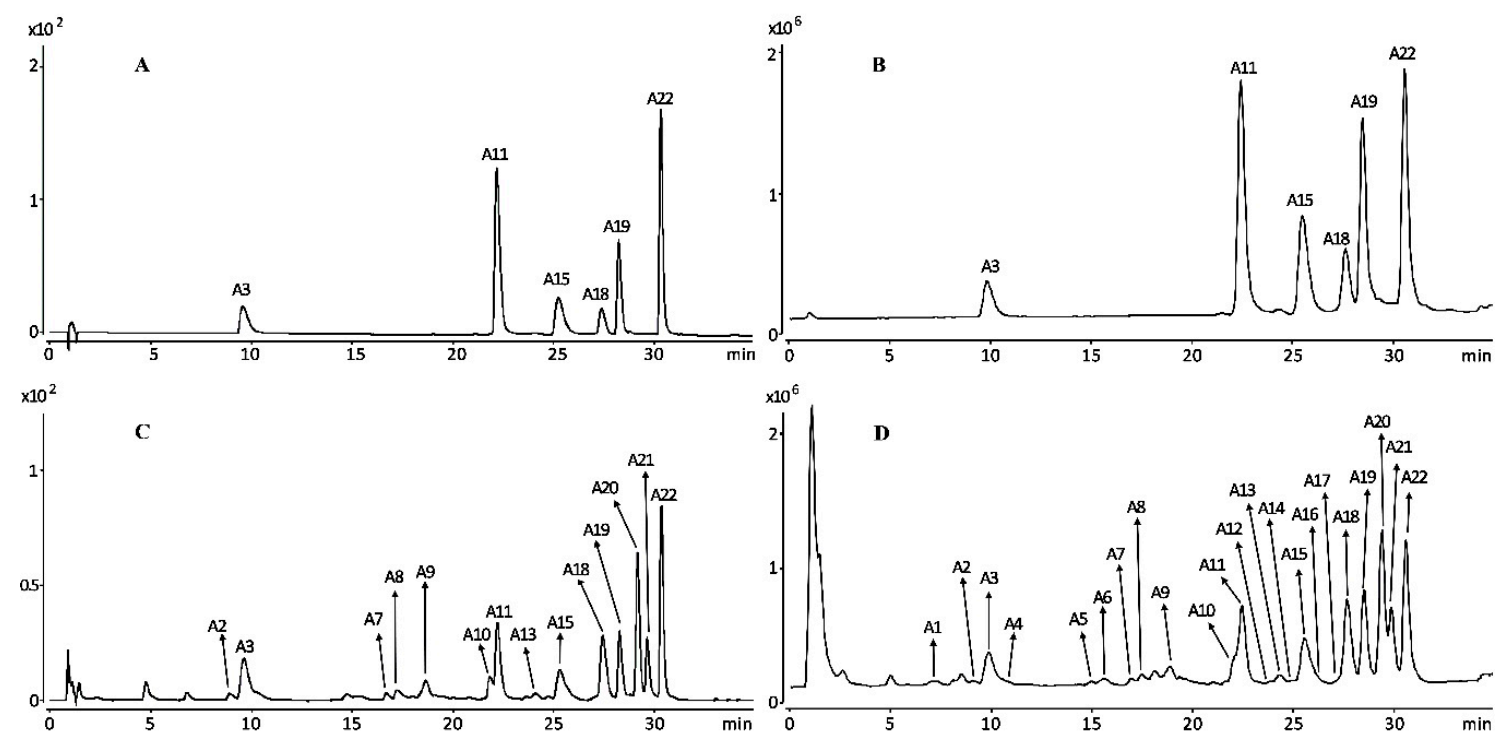

Figure 1. Chromatograms $(\mathbf{A}, \mathbf{C})$ and total ion chromatograms (B,D) of standards and samples of Iris lactea ((A,B): Standard; (C,D): Sample). A3: mangiferin, A11: embinin, A15: irislactin C, A18: embinin A, A19: irislactin A and A22: embinin C. 
Table 1. Characterization of chemical constituents of Iris lactea by HPLC-DAD-Q-TOF-MS/MS

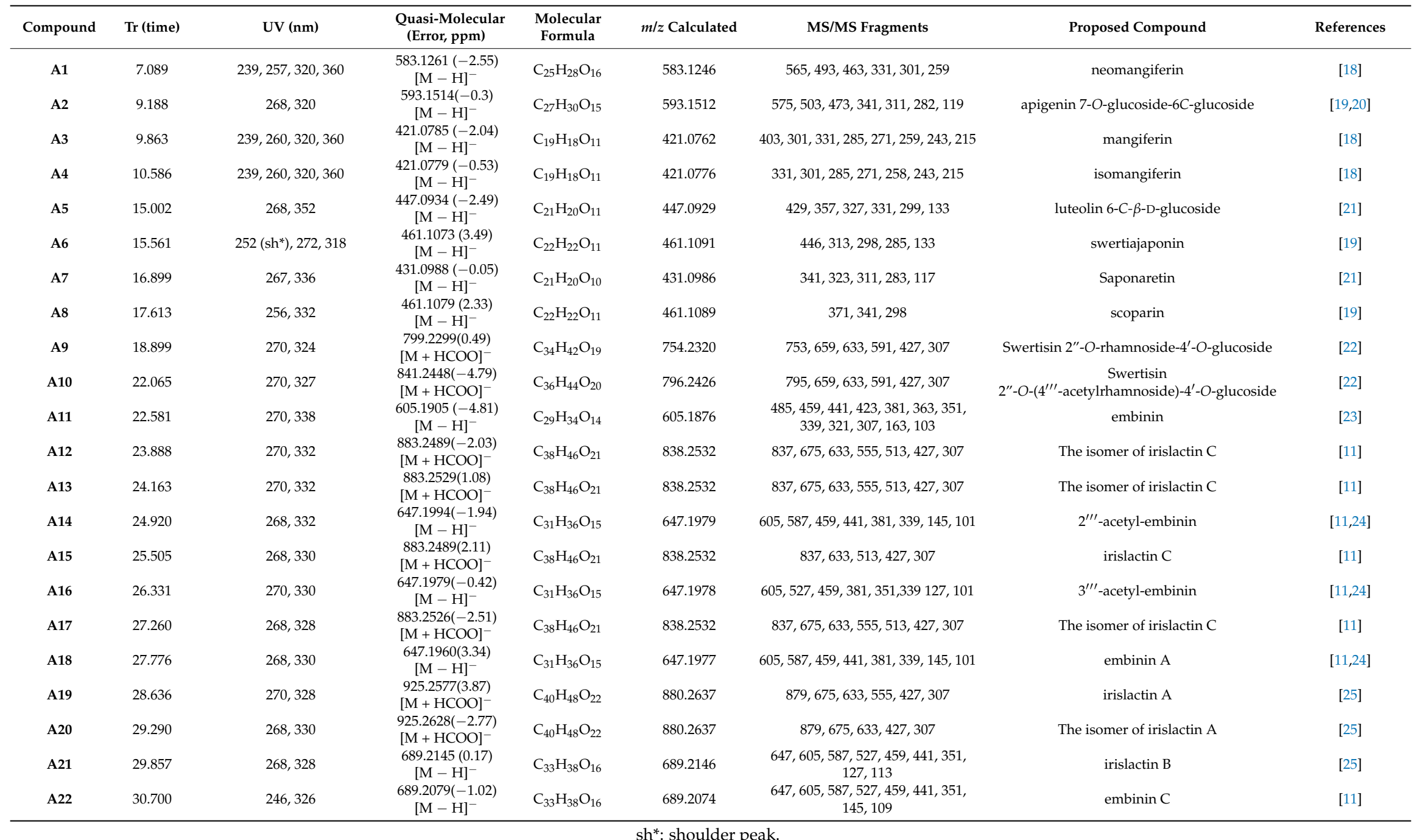


Compounds A1, A3 and A4 possessed similar maximum absorptions of about 239 (shoulder peak), 260 (or 257), 320 and $360 \mathrm{~nm}$, which are characteristic UV features of xanthones. The fragment ions of compound A3 showed $331[\mathrm{M}-\mathrm{H}-90]^{-}, 301[\mathrm{M}-\mathrm{H}-120]^{-}$and $271[\mathrm{M}-\mathrm{H}-150]^{-}$, which are typical of $C$-glucosides [18]. By comparing with mass spectra of a reference standard and previously reported data [18], A3 was identified as mangiferin. By a similar method, compounds A1 and A4 were tentatively identified as neomangiferin and isomangiferin, respectively [18].

Compounds A2 and A5-A22 showed similar UV spectra with absorption maxima at 240-280 and $320-360 \mathrm{~nm}$, and a similar fragmentation pattern, which showed successive losses of 60, 90 and $120 \mathrm{Da}$, which is typical of flavone $C$-glucosides [18]. Compound A2 (m/z $593.1514\left[\mathrm{M}-\mathrm{H}^{-}\right)$ exhibited UV absorption peaks at 268 and $320 \mathrm{~nm}$ and the molecular formula $\mathrm{C}_{27} \mathrm{H}_{30} \mathrm{O}_{15}$, which indicated that it was a flavone; fragment ions at $m / z 503[\mathrm{M}-\mathrm{H}-90]^{-}$and $473[\mathrm{M}-\mathrm{H}-120]^{-}$ indicated that A2 was a flavone C-glucoside, and the fragment ions at $341[\mathrm{M}-\mathrm{H}-90-$ $162]^{-}$and 311 [M $\left.-\mathrm{H}-120-162\right]^{-}$showed that it was also a O-glucoside, as did the fragment ion at $m / z 119$ and related references [19,20]. Compound A2 was thus tentatively identified as apigenin-7-O-glucoside-6- $C$-glucoside. By a similar method, compounds A5-A9 were tentatively identified as luteolin-6-C- $\beta$-D-glucoside, swertiajaponin, saponaretin, scoparin and swertisin-2"-O-rhamnoside-4'-O-glucoside, respectively [19,21,22]. Compound A10 exhibited the same fragmentation pathway as $\mathbf{A 9}$, but had a higher molecular weight (42 Da); using information from the literature [22], A10 was tentatively identified as swertisin-2" $-O-\left(4^{\prime \prime \prime}\right.$-acetylrhamnoside)-4'-O-glucoside.

Compound A11 showed a molecular ion at $\mathrm{m} / \mathrm{z} 605.1905[\mathrm{M}-\mathrm{H}]^{-}$, and fragment ions at $\mathrm{m} / \mathrm{z}$ $459[\mathrm{M}-\mathrm{H}-146]^{-}$and $339[\mathrm{M}-\mathrm{H}-120-146]^{-}$, which indicated that it was a $O$-rhamnoside. The fragment ions at $m / z 485[\mathrm{M}-\mathrm{H}-120]^{-}, 441[\mathrm{M}-\mathrm{H}-146-18]^{-}, 381[\mathrm{M}-\mathrm{H}-146-18$ $-60]^{-}, 351[\mathrm{M}-\mathrm{H}-146-18-90]^{-}$and $321[\mathrm{M}-\mathrm{H}-146-18-120]^{-}$showed that $\mathbf{A 1 1}$ was a C-glucoside; in addition, it showed other fragment ions at $\mathrm{m} / \mathrm{z} 307,163$ and 103. By comparing an authentic standard and the corresponding UV and MS data with literature values [23], A11 was unambiguously identified as embinin. Compounds A18 and A22 showed a similar fragmentation pathway to, but possessed one or two more acetyl groups than compound A11. By comparison with authentic standards and literature data [11,24], compounds A18 and A22 were identified as $4^{\prime \prime \prime}$-acetyl-embinin and embinin C, respectively. Compounds A14, A16 and A21 were isomers of irislactin C, which showed a similar fragmentation pathway to A18. The main differences in these compounds were the different substitutions of the acetyl groups. Combined with the molecular weight, retention time and literature [10,24,25], compounds A14, A16 and A21 were tentatively identified as $2^{\prime \prime \prime}$-acetyl-embinin, $3^{\prime \prime \prime}$-acetyl-embinin and irislactin $\mathrm{B}$, respectively.

Compound $\mathbf{A 1 5}$ had a molecular ion at $m / z 883.2489\left[\mathrm{M}+\mathrm{HCOO}^{-}\right.$, a similar fragmentation pattern to compound A11 and a base peak at $m / z 633$ [M $-\mathrm{H}-162-42]^{-}$; it also had a fragment ion at $m / z 675$ [M $-\mathrm{H}-162]^{-}$which was not tested, so we speculated that A15 possessed a glucoside residue connected with an acetyl group. Fragment ions at $m / z 717[\mathrm{M}-\mathrm{H}-120]^{-}, 513[\mathrm{M}-\mathrm{H}-162$ $-42-120]^{-}, 427[\mathrm{M}-\mathrm{H}-162-42-42-146-18]^{-}$and $307[\mathrm{M}-\mathrm{H}-162-42-42-146-$ $18-120]^{-}$were found in A15. By comparing the authentic standards and their corresponding UV and MS data with literature values [11], A15 was unambiguously identified as irislactin C. Compounds A12, A13 and A17 possess the same molecular formula as compound A15, and showed a similar fragmentation pathway to A15, therefore Compounds A12, A13 and A17 were tentatively identified as the isomers of irislactin C. Compound A19 showed a molecular ion at $m / z 925.2628[\mathrm{M}+\mathrm{HCOO}]^{-}$, and possessed the same pathway as A15. By comparing the molecular weight, authentic standards and their corresponding UV and MS data with literature values [25], A19 was unambiguously identified as irislactin A. Compound A20 showed the same molecular formula and a similar fragmentation pathway to A19, Thus compound A20 was tentatively identified as an isomer of irislactin A.

Twenty-two compounds including three xanthones and nineteen flavones were thus identified or tentatively identified from I. lactea leaves. All constituents identified were $C$-glycosylflavones, including twelve acetylated $C$-glycosylflavones. The literature reports indicate that $C$-glycosylflavones are widely 
distributed in plant kingdom, and found in algae, bryophytes, ferns, gymnosperms and angiosperms, involving hundreds of species of plants from different families and genera, such as Characeae, Conocephalaceae, Psilotaceae, Cycadaceae and Compositae, etc [26]. These kinds of ingredients show various pharmacological activities, including anti-oxidant [27], anti-inflammatory [28], anti-diabetes [29], anti-tumor [30], anti-virus [31], cardiovascular protection [32], liver-protection [33] and memory amelioration [34]. Among the compounds identified from I. lactea leaves, mangiferin showed good anti-inflammatory, anti-diabetes, and anti-tumor pharmacological activity, and is one of the hotspots in current studies [35,36], while acetylated C-glycosylflavones showed poor activity in the literature $[11,25]$. On the whole, the $C$-glycosylflavones are worthy of further study.

\subsection{Optimization of the Extraction Process}

When the degree of comminution reached 80-mesh, the extraction ratio increased slowly (Figure S2a). Thus, 80-mesh was chosen as one of the optimal extraction parameters after considering the centrifugation, filtration and other experimental factors. The total peak area of target components for three different extraction methods showed no significant difference (Figure S2b). However, ultrasound extraction was finally chosen for optimization because the methods of soaking and hot reflux were more operation-complex and time-consuming. The extraction efficiency of methanol was higher than that of ethanol at the same concentration (Figure S2c). Moreover, with increasing solvent concentration, the extraction efficiency initially increased and then decreased. Therefore, $40-80 \%$ methanol solution was selected as solvent range for response surface design $[37,38]$. In the investigation of liquid-solid ratio, extraction efficiency improved with the increase of liquid volume but with no obvious difference between 20 and $25 \mathrm{~mL}$ of methanol (Figure S2d). For reasons of experimental cost, the liquid-solid ratio of 1:15-1:25 was chosen for response surface optimization. In addition, with the increase of extraction time, the total peak area of target components rose progressively more slowly (Figure S2e). Consequently, extraction time of 15-45 min was selected as the level of response surface design. In assessment of extraction frequency, the total peak area presented an increasing trend, but the efficiency of three extractions was almost the same as that for two (Figure S2f). Hence, the frequency of two extractions was chosen for optimization [39].

Subsequently, the extraction parameters were further optimized by Box-Behnken design experiment. The data displayed in Table S1 were fitted to a quadratic polynomial model using response surface methodology.

The obtained encoding equation was as follows:

$$
\mathrm{Y}=3.75+0.24 \mathrm{~A}+0.066 \mathrm{~B}+0.060 \mathrm{C}-0.010 \mathrm{AB}-0.018 \mathrm{AC}+0.17 \mathrm{BC}-0.40 \mathrm{~A}^{2}-0.11 \mathrm{~B}^{2}-0.11 \mathrm{C}^{2}
$$

and the true-value equation was as follows:

$$
\begin{gathered}
\mathrm{Y}=-2.00075+1.34 \mathrm{~A}+0.13 \mathrm{~B}-8.23 \times 10^{-3} \mathrm{C}-1.0 \times 10^{-4} \mathrm{AB}-5.83 \times 10^{-5} \mathrm{AC}+2.23 \times \\
10^{-3} \mathrm{BC}-9.9 \times 10^{-4} \mathrm{~A}^{2}-4.44 \times 10^{-3} \mathrm{~B}^{2}-4.82 \times 10^{-4} \mathrm{C}^{2}
\end{gathered}
$$

where $\mathrm{Y}$ is the extraction efficiency of the main active components in I. lactea leaves (shown by the total peak area of six main components), and variables $A, B$ and $C$ represent the methanol concentration $(\%)$, liquid-solid ratio ( $\left.\mathrm{mL} \cdot(0.5 \mathrm{~g})^{-1}\right)$ and extraction time, respectively.

To verify the feasibility of the regression equation, significance $(\alpha=0.05)$ of the model and coefficient was tested (Tables S2 and S3). The $p$ value $(<0.0001)$ and correlation coefficient $\left(R^{2}=0.9977\right)$ of the model demonstrated the extreme significance of the regression model and linear relationship between $\mathrm{Y}$ and the dependent variable. Additionally, the lack of fit $(p=0.0759>0.05)$ also suggested that this equation had a good fit and little deviation for corresponding true values. Thus, this model could be used to adequately evaluate the experimental results. Because the $p$ values of the regression coefficients of variables (A, B and C), as well as their interaction (BC) and quadratic effects $\left(\mathrm{A}^{2}, \mathrm{~B}^{2}\right.$ and 
$C^{2}$ ) were less than 0.0001 , this implied that they significantly affected the $Y$ value, but their interactions $(\mathrm{AB}$ and $\mathrm{AC}$ ) did not ( $p$ values of 0.3845 and 0.1486 , respectively, i.e., $>0.05$ ).

Subsequently, the 3D response surface and the corresponding 2D contour map (Figure S3) were used to further analyze the factor interactions, where the steeper the curve is, the greater effect the factor has on the response value. When methanol concentration was constant, the liquid-solid ratio had no obvious influence on extraction efficiency; when the liquid-solid ratio was constant, the methanol concentration initially increased and then decreased (Figure S3a). The extraction efficiency changed gently with time, increasing with rising methanol concentration up to a certain value and subsequently decreasing (Figure S3b). The combined influence of liquid-solid ratio and extraction time had a slight impact on extraction efficiency (Figure S3c). In summary, the optimal conditions for maximum response values, calculated via Design-Expert, were methanol concentration of $65.16 \%$, liquid-solid ratio of 25.73:1 and extraction time of $47.07 \mathrm{~min}$. For convenience and less cost, the corresponding optimum values were $65 \%, 25: 1$ and $47 \mathrm{~min}$, for which the true value was only $2 \%$ lower than the predicted value.

\subsection{Optimization of Chromatographic Conditions}

To optimize the chromatographic separation efficiency, several influence factors of detection wavelengths (254 nm and $270 \mathrm{~nm}$ ), mobile phase (methanol/(acid) water and acetonitrile/(acid) water), column temperature $\left(25^{\circ} \mathrm{C}, 30^{\circ} \mathrm{C}\right.$ and $\left.35^{\circ} \mathrm{C}\right)$, flow rate $\left(0.8 \mathrm{~mL} \cdot \mathrm{min}^{-1}\right.$ and $\left.1 \mathrm{~mL} \cdot \mathrm{min}^{-1}\right)$ and injection volume $(10 \mu \mathrm{L}, 15 \mu \mathrm{L}$ and $20 \mu \mathrm{L})$ were tested. The optimized parameters were selected as mobile phases of $0.1 \%$ formic acid-water (A) and acetonitrile (B), flow rate of $0.8 \mathrm{~mL} \cdot \mathrm{min}^{-1}$, column temperature of $30^{\circ} \mathrm{C}$, injection volume of $15 \mu \mathrm{L}$, detection wavelength of $270 \mathrm{~nm}$ and program run time of $45 \mathrm{~min}$ after comparing the peak shape and analysis time.

\subsection{Method Validation}

\subsubsection{Linearity and Limits of Detection (LOD) and Quantitation (LOQ)}

The calibration curves of the six reference compounds of mangiferin, embinin, irislactin $C$, irislactin A, embinin A and embinin $\mathrm{C}$ were drawn using the results of determination (Figure S4). The calibration curve, correlation coefficient, linear range, LOD and LOQ of each reference compound were obtained (Table 2), and the reference compounds both showed a good linear relationship $\left(R^{2} \geq 0.9998\right)$ within the test ranges.

Table 2. Calibration curves, liner range, LOD and LOQ of six reference compounds.

\begin{tabular}{|c|c|c|c|c|c|}
\hline Analyte & Calibration Curves & $\mathrm{R}^{2}$ & $\begin{array}{l}\text { Liner Range } \\
\left(\mu \mathrm{g} \cdot \mathrm{mL}^{-1}\right)\end{array}$ & $\begin{array}{c}\text { LOD } \\
\left.\text { (ng } \cdot \mathrm{mL}^{-1}\right)\end{array}$ & $\begin{array}{c}\mathrm{LOQ} \\
\left(\mathrm{ng} \cdot \mathrm{mL}^{-1}\right)\end{array}$ \\
\hline Mangiferin & $y=37119 x-13.767$ & 0.9998 & $3.74-22.44$ & 26.7 & 93.5 \\
\hline Embinin & $y=25969 x-13.174$ & 0.9999 & $4.40-198.00$ & 11.5 & 16.5 \\
\hline Irislactin C & $y=19575 x-1.0423$ & 0.9999 & $2.21-100.00$ & 3.9 & 8.3 \\
\hline Irislactin A & $y=21296 x+0.0506$ & 0.9998 & $2.52-113.40$ & 16.7 & 31.5 \\
\hline Embinin A & $y=33469 x-3.9068$ & 0.9999 & $3.36-37.10$ & 23.6 & 84.0 \\
\hline Embinin C & $y=25250 x-2.1531$ & 0.9999 & $4.00-180.00$ & 8.9 & 15.0 \\
\hline
\end{tabular}

\subsubsection{Precision, Repeatability, Stability and Recovery}

The relative standard deviations (RSDs) of intra- and inter-day precision, repeatability and stability investigation of mangiferin, embinin, irislactin $C$, irislactin A, embinin $A$ and embinin $C$ were all $<2 \%$, indicating that our method had good precision, repeatability and stability (Tables S4-S7). Additionally, the recovery range of $97-101 \%$ (RSD $<3 \%$ ) indicated high recovery and reliability (Table S8). 


\subsection{Quantitative Analysis of HPLC-DAD for Flavonoids of I. lactea Leaves}

Using the chromatograms, the six main components of I. lactea leaves from different regions were quantitatively analyzed, where the variation ranges of mangiferin, embinin, irislactin $C$, irislactin A, embinin A and embinin C were 0.48-2.16, 0.88-11.78, 0.75-5.56, 0.77-3.11, 0.92-6.67 and $0.49-12.38 \mathrm{mg} \cdot \mathrm{g}^{-1}$, respectively (Table 3 ). The contents of mangiferin and irislactin A varied narrowly, but those of embinin, embinin $A$, irislactin $C$ and embinin $C$ varied widely; the results indicated that the contents of tested compounds of different samples showed certain differences. The total contents of six main components in the samples from Nanjing (S3), Tianjin (S6) and Haidian, Beijing (S10) had the higher content $\left(>20 \mathrm{mg} \cdot \mathrm{g}^{-1}\right)$, samples from Liaoning (S14) had the lowest content $\left(<15 \mathrm{mg} \cdot \mathrm{g}^{-1}\right)$ and the majority of samples were a relatively stable. $\left(15-20 \mathrm{mg} \cdot \mathrm{g}^{-1}\right)$ (Figure 2).

Table 3. Contents of six components in I. lactea leaves from different regions (Mean $\pm \mathrm{SD}, \mathrm{mg} / \mathrm{g}, n=3$ ).

\begin{tabular}{ccccccc}
\hline No. & Mangiferin & Embinin & Irislactin C & Irislactin A & Embinin A & Embinin C \\
\hline S1 & $1.60 \pm 0.01$ & $1.14 \pm 0.01$ & $1.68 \pm 0.01$ & $0.88 \pm 0.01$ & $4.79 \pm 0.03$ & $6.74 \pm 0.08$ \\
S2 & $1.52 \pm 0.01$ & $2.14 \pm 0.01$ & $2.46 \pm 0.01$ & $1.64 \pm 0.00$ & $2.66 \pm 0.02$ & $5.26 \pm 0.02$ \\
S3 & $1.71 \pm 0.00$ & $2.78 \pm 0.01$ & $0.90 \pm 0.01$ & $2.57 \pm 0.01$ & $2.15 \pm 0.01$ & $12.38 \pm 0.02$ \\
S4 & $1.24 \pm 0.02$ & $1.39 \pm 0.01$ & $2.15 \pm 0.03$ & $1.16 \pm 0.01$ & $3.60 \pm 0.05$ & $6.29 \pm 0.06$ \\
S5 & $1.72 \pm 0.01$ & $0.91 \pm 0.00$ & $4.31 \pm 0.04$ & $0.85 \pm 0.01$ & $6.09 \pm 0.03$ & $2.90 \pm 0.00$ \\
S6 & $1.80 \pm 0.01$ & $3.75 \pm 0.01$ & $3.20 \pm 0.02$ & $3.11 \pm 0.01$ & $3.41 \pm 0.03$ & $6.32 \pm 0.02$ \\
S7 & $0.69 \pm 0.01$ & $5.39 \pm 0.01$ & $0.75 \pm 0.00$ & $2.12 \pm 0.01$ & $0.92 \pm 0.01$ & $6.21 \pm 0.07$ \\
S8 & $1.23 \pm 0.02$ & $2.85 \pm 0.04$ & $1.67 \pm 0.02$ & $2.43 \pm 0.02$ & $2.99 \pm 0.02$ & $7.80 \pm 0.10$ \\
S9 & $1.16 \pm 0.01$ & $2.19 \pm 0.03$ & $1.95 \pm 0.02$ & $1.68 \pm 0.01$ & $2.80 \pm 0.03$ & $5.66 \pm 0.01$ \\
S10 & $0.48 \pm 0.01$ & $11.78 \pm 0.03$ & $4.57 \pm 0.03$ & $2.42 \pm 0.07$ & $1.36 \pm 0.03$ & $2.30 \pm 0.01$ \\
S11 & $1.31 \pm 0.05$ & $2.75 \pm 0.01$ & $2.66 \pm 0.00$ & $1.44 \pm 0.02$ & $4.23 \pm 0.05$ & $5.60 \pm 0.02$ \\
S12 & $1.01 \pm 0.01$ & $2.29 \pm 0.02$ & $2.22 \pm 0.01$ & $1.39 \pm 0.00$ & $4.54 \pm 0.02$ & $8.08 \pm 0.03$ \\
S13 & $1.72 \pm 0.03$ & $0.88 \pm 0.01$ & $4.43 \pm 0.06$ & $0.86 \pm 0.02$ & $6.67 \pm 0.05$ & $3.14 \pm 0.01$ \\
S14 & $2.16 \pm 0.01$ & $2.59 \pm 0.03$ & $5.56 \pm 0.02$ & $0.77 \pm 0.01$ & $1.68 \pm 0.03$ & $0.49 \pm 0.02$ \\
\hline
\end{tabular}

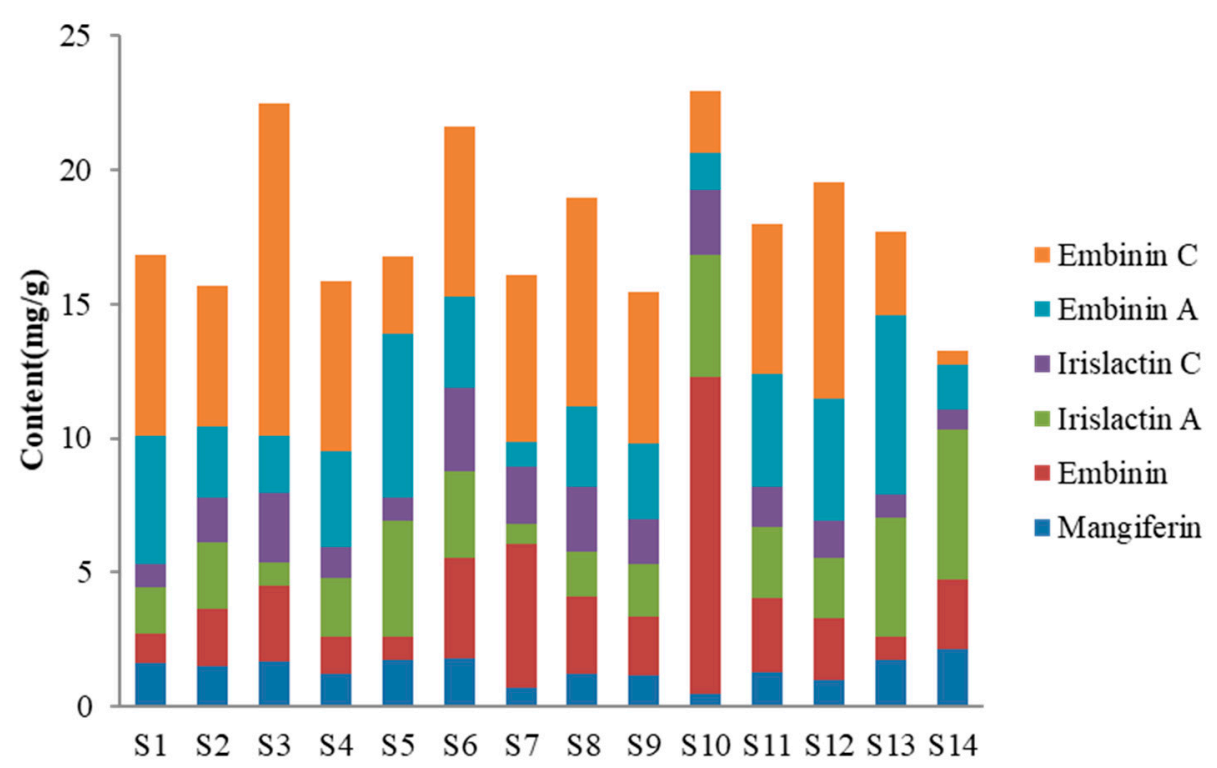

Figure 2. Total contents of main components in Iris lactea leaves from different areas.

In addition, even in the same area, the total contents of six main components in leaves of different batches were statistically different (Tables 3 and 4). For instance, in I. lactea leaves collected from Nanjing, Jiangsu, the total content of six main components in smple S3 was higher than that of samples S1 and S2. Similarly, the total content of sample S10, gathered from Haidian, Beijing, was higher than that of sample S9 from Dongcheng District, Beijing. The total content of sample S6 (Tianjin) was higher than that of sample S5 (Jixian County, Tianjin). The reason for the differences in total contents is likely 
such factors as geographical location of sampling such as sample S3 and S13, sample S10 and S11, the phenological influence such as sample S1-S3, samples S13 and S14, and chemical transformations among compounds. In previous study, we found the phenomenon that some compounds had mutual transitions, such as irislactin A and embinin C [11]. In addition to the above factors, there may be other factors affecting the change of chemical composition content, which needs to be further studied and analyzed.

Table 4. Information for the investigated samples.

\begin{tabular}{cccccccc}
\hline No. & Habitat & Collection & Collection Time & No. & Habitat & Collection & Collection Time \\
\hline S1 & Jiangsu & Nanjing & 2015.04 & S8 & Shaanxi & Xi'an & 2015.05 \\
S2 & Jiangsu & Nanjing & 2015.04 & S9 & Beijing & Dongcheng & 2015.05 \\
S3 & Jiangsu & Nanjing & 2015.05 & S10 & Beijing & Haidian & 2015.05 \\
S4 & Henan & Zhengzhou & 2015.04 & S11 & Shandong & Zaozhuang & 2015.05 \\
S5 & Tianjin & Jixian & 2015.04 & S12 & Shandong & Zaozhuang & 2015.05 \\
S6 & Tianjin & Tianjin & 2015.04 & S13 & Liaoning & Huludao & 2015.05 \\
S7 & Shanghai & Shanghai & 2015.04 & S14 & Liaoning & Chaoyang & 2014.09 \\
\hline \multicolumn{7}{c}{ All samples dried in the sun. }
\end{tabular}

\section{Materials and Methods}

\subsection{Chemicals and Plant Material}

The standards of mangiferin, embinin, irislactin C, irislactin A, embinin A and embinin C were made in our laboratory. The purity of each compound was determined to be higher than $96 \%$ by NMR, MS and area normalization method. Chromatographic grade methanol and formic acid were purchased from Nanjing Chemical Reagents Co. Ltd. (Nanjing, China). Acetonitrile was purchased from Merck (Darmstadt, Germany). Wahaha pure water was obtained from Hangzhou Wahaha Group Co. Ltd. (Hangzhou, China). Sample information for I. lactea leaves is shown in Table 4.

\subsection{Preparation of Samples and Standard Solutions}

The sample solution was prepared by extracting the powder of I. lactea leaves (accurately weighed $0.50 \mathrm{~g}$ ) in $20 \mathrm{~mL}$ of $70 \%$ methanol. Then, supernatant volume was amalgamated and shaken in a 50-mL volumetric flask after two ultrasonic extractions at $25^{\circ} \mathrm{C}, 100 \mathrm{~W}$ for 45 min (Kunshan Wo Chuang Ultrasonic Instrument Co. Ltd., Kunshan, China) and centrifuged for $20 \mathrm{~min}$ at $12000 \mathrm{rpm}$. Subsequently, the solution was stored in a refrigerator at $4{ }^{\circ} \mathrm{C}$ and filtered through a $0.22 \mu \mathrm{m}$ membrane (Tianjin Xinxian Technology Co. Ltd., Tianjin, China) filter until analysis.

The standards of mangiferin $(0.22 \mathrm{mg})$, embinin $(1.27 \mathrm{mg})$, irislactin C $(2.10 \mathrm{mg})$, irislactin A $(2.10 \mathrm{mg})$, embinin A (1.12 mg) and embinin C (2.50 mg) were accurately weighed. Next, they were individually dissolved in a 2-mL volumetric flask in methanol. Each standard solution was obtained after adjusting to a constant volume. The mixed standard solution was obtained by appropriately mixing each standard solution in a 2-mL volumetric flask for mangiferin $\left(0.02244 \mathrm{mg} \cdot \mathrm{mL}^{-1}\right)$, embinin $\left(0.198 \mathrm{mg} \cdot \mathrm{mL}^{-1}\right)$, irislactin $C\left(0.100 \mathrm{mg} \cdot \mathrm{mL}^{-1}\right)$, embinin A $\left(0.1134 \mathrm{mg} \cdot \mathrm{mL}^{-1}\right)$, irislactin A $\left(0.0371 \mathrm{mg} \cdot \mathrm{mL}^{-1}\right)$, embinin $\mathrm{C}\left(0.180 \mathrm{mg} \cdot \mathrm{mL}^{-1}\right)$. These were stored in a refrigerator at $4{ }^{\circ} \mathrm{C}$ and filtered through a $0.22 \mu \mathrm{m}$ membrane filter until analysis.

\subsection{Qualitative Analysis of HPLC-Q-TOF-MS/MS for Chemical Constituents of I. lactea Leaves}

Chromatographic analyses were performed using a high performance liquid chromatograph (Agilent Technologies Inc., Santa Clara, CA, USA) coupled to an electrospray ionization (ESI) mass spectrometer (Agilent Technologies Inc., Santa Clara, CA, USA). Chromatographic separation was conducted on an Agilent Zorbax SB-C18 column $(3.0 \mathrm{~mm} \times 150 \mathrm{~mm}, 3.5 \mu \mathrm{m})$. The mobile phases consisted of $0.1 \%$ formic acid-water (A) and acetonitrile (B), and the gradient elution program was set as follows: $0 \mathrm{~min}, 5 \% \mathrm{~B}$; 5-10 $\mathrm{min}, 11 \% \mathrm{~B} ; 15 \mathrm{~min}, 19 \% \mathrm{~B} ; 20-24 \mathrm{~min}, 24 \% \mathrm{~B} ; 25 \mathrm{~min}, 27 \% \mathrm{~B} ; 28 \mathrm{~min}$, 
$35 \% \mathrm{~B} ; 30 \mathrm{~min}, 38 \% \mathrm{~B}$ and $35 \mathrm{~min}, 70 \% \mathrm{~B}$. The flow rate was $0.8 \mathrm{~mL} \cdot \mathrm{min}^{-1}$, injection volume was $15 \mu \mathrm{L}$, column temperature was $30^{\circ} \mathrm{C}$ and detection wavelength was $270 \mathrm{~nm}$. The ESI was applied in negative ion modes for mass analysis and detection. The optimized parameters were as follows: capillary voltage, $3000 \mathrm{~V}$; conical-hole voltage, $60 \mathrm{~V}$; nebulizing-gas pressure, $35 \mathrm{psi}$; drying-gas flow rate, $10 \mathrm{~L} \cdot \mathrm{min}^{-1}$; drying-gas temperature, $320^{\circ} \mathrm{C}$; and mass spectral range, $m / z$ 100-2000.

\subsection{Optimization of the Extraction Process}

\subsubsection{Single Factor Experiments}

Single factor tests were carried out to optimize the flavonoid extraction. The extraction conditions showed as follows. Powder of I. lactea leaves ( $0.5 \mathrm{~g}$, Sample S6) was used. Comminution degree $(20,40$, 60, 80 and $100 \mathrm{mesh}$ ), extraction method (soak for $12 \mathrm{~h}$, ultrasonication for $30 \mathrm{~min}$ at room temperature and reflux $1 \mathrm{~h}$ at $\left.80{ }^{\circ} \mathrm{C}\right)$, methanol/ethanol concentration (40,60, 80 and 100\%), liquid-solid ratio (10, 15,20 and $25 \mathrm{~mL}$ of methanol), extraction time $(15,30,45$ and $60 \mathrm{~min})$ and frequency $(1,2$ and 3$)$ were investigated, respectively. Each level was run in triplicate. When one of the factors was experimented, conditions of other factors were the same as "3.2 Preparation of Samples". The optimal extraction conditions were preliminarily chosen according to total contents of mangiferin, embinin, irislactin C, irislactin A, embinin A and embinin C determined by HPLC.

\subsubsection{Box-Behnken Response-Surface Design Experiment}

Box-Behnken design conducted using Design-Expert software (version 8.0.6, Stat-Ease Inc., Minneapolis, MN, USA) (Table S9) was chosen for optimized extraction of flavonoids in I. lactea leaves based on results of single factor experiments. Since it is much more efficient than the three-level full factorial designs [40]. Each factor was set as the following levels: methanol concentration $(40,60$ and $80 \%)(A)$, liquid-solid ratio (15:1, 20:1 and 25:1) (B) and extraction time (15, 30 and $45 \mathrm{~min})(\mathrm{C})$.

\subsection{Method Validation}

\subsubsection{Preparation of Sample Solution}

The sample solution was prepared based on the result of the Box-Behnken response-surface design experiment. Powder of I. lactea leaves $(0.5 \mathrm{~g}$, sample S6) was accurately weighed and extracted in $25 \mathrm{~mL}$ of $65 \%$ methanol. Subsequently, supernatant volume was amalgamated and shaken in a $50 \mathrm{~mL}$ volumetric flask after twice ultrasonic extractions and centrifuged for $20 \mathrm{~min}$ at $12000 \mathrm{rpm}$. The extract was stored in a refrigerator at $4{ }^{\circ} \mathrm{C}$ and filtered through a $0.22 \mu \mathrm{m}$ membrane filter until analysis.

\subsubsection{Linearity, LOD and LOQ}

The mixed standard solutions in nine different concentrations were prepared by gradient dilution with methanol prior to analysis using HPLC. The least squares method was used for regression analysis, with injection concentration $\left(\mathrm{mg} \cdot \mathrm{mL}^{-1}\right.$ ) as the abscissa and peak area of the index components as the ordinate. The mixed standard solution was diluted by methanol to determine the LOD and LOQ. The concentrations when the ratios of sign-to-noise were 3:1 and 10:1 were selected as the LOD and LOQ, respectively.

\subsubsection{Precision, Repeatability, Stability and Recovery}

Five repeated injections of the mixed standard solution in the same day and three repeated injections per day for three consecutive days were used to evaluate of intra- and inter-day precision, respectively. Six sample solutions were prepared independently to check repeatability. The sample solution was injected at $0,4,8,12,24,48$ and $72 \mathrm{~h}$ separately for analysis of stability. To investigate recovery, six sample solutions prepared by adding mixed standard solution to $0.25 \mathrm{~g}$ of I. lactea leaves (S6) were analyzed. 


\subsection{Quantitative Analysis of HPLC-DAD for Flavonoids of I. lactea Leaves}

Quantitative analysis of six main components of I. lactea leaves from different producing areas was performed individually by HPLC-DAD based on the optimum extract parameters. Contents of six components in different samples were calculated via linear regression equation.

\subsection{Data Analysis}

All data were collected and analyzed using Masshunter Qualitative Analysis Software B 03.00 ChemStation software (Agilent Technologies Inc., Santa Clara, CA, USA). Data treatment was carried out using Microsoft Excel software (Microsoft Corp., Redmond, WA, USA) and IBM SPSS software 22.0 (IBM Corp., Armonk, NY, USA).

\section{Conclusions}

HPLC-Q-TOF-MS/MS was used to qualitatively analyze the constituents of I. lactea leaves, and 22 C-glycosylflavones were identified or tentatively identified. If a more detailed classification is desired, compounds A1, A4 and $\mathbf{A} 5$ belong to the xanthone $C$-glycosides, and the other compounds are flavone C-glycosides, especially, compounds A10 and A12-A22 which belong to the flavone C-glycosides with acetyl groups. According to the literatures and our studies [11,25], we found the flavone C-glycosides with acetyl groups are the characteristic ingredients of I. lactea leaves, and these types of compounds may possess chemotaxonomic significance to distinguish I. lactea from the other genera.

After optimizing the extraction method, 14 batches of I. lactea leaves gathered from 10 different growing districts in eight Chinese provinces were quantitatively analyzed. The results showed the C-glycosylflavones were the main components of I. lactea leaves, and the total contents of detected components were relatively stable for the majority of samples. Among them, the samples from Nanjing (sample S3), Tianjin (sample S6) and Haidian, Beijing (sample S10) had the higher content $\left(>20 \mathrm{mg} \cdot \mathrm{g}^{-1}\right.$ ), samples from Liaoning (sample S14) had the lowest content $\left(<15 \mathrm{mg} \cdot \mathrm{g}^{-1}\right)$ (Figure 2). This might be caused by geographical location of sampling, phenological information and chemical transformations between compounds. These relevant factors will need to be investigated, analyzed and optimized to improve quality of I. lactea.

Supplementary Materials: The following are available online, Figure S1: Structure of the twenty-two compounds, Figure S2: Results of single factor experiments, Figure S3: RMS plots for the interaction of the variables in 3D and 2D, Figure S4: Calibration curves of six reference compounds, Table S1: Program and test of RSM, Table S2: Analysis of variance for quadratic model, Table S3: Test result of significance for regression coefficient, Table S4: Results of intra-day precision test, Table S5: Results of inter-day precision test, Table S6: Results of repeatability test, Table S7: Results of stability test, Table S8: Results of recovery test, Table S9: Levels of the response surface test.

Author Contributions: Conceptualization, M.Q.; Data curation, G.X.; Formal analysis, Y.M.; Funding acquisition, M.Q. and G.X.; Investigation, Y.M. and G.X.; Methodology, D.C. and Y.M.; Project administration, M.Q.; Resources, Y.Z.; Software, Y.Z. and J.Y.; Supervision, G.X.; Validation, G.W.; Visualization, D.C.; Writing-original draft, D.C. and G.X.

Funding: We acknowledge the financial supports of the National Natural Science Foundation of China (Grant No. 81503220), the National Natural Science Foundation of Jiangsu province (Grant No. BK20150706), and Jiangsu Key Laboratory of Regional Resource Exploitation and Medicinal Research (No. LPRK201705, LPRK201704).

Conflicts of Interest: The authors declare no conflict of interest. 


\section{References}

1. The Editorial Committee of Chinese Materia Medica, State Administration of Traditional Chinese Medicine. Chinese Materia Medica; Shanghai Scientific and Technical Publishers: Shanghai, China, 1999; Volume 22, pp. 271-275.

2. Lv, H.; Wang, H.; He, Y.; Ding, C.; Wang, X.; Suo, Y. Separation and purification of four oligostilbenes from iris lactea, pall. var. chinensis, (fisch.) koidz by high-speed counter-current chromatography. J. Chromatogr. B 2015, 988, 127-134. [CrossRef] [PubMed]

3. Jiang, X.G.; Hou, D.Y.; Weng, X.; Wang, C.Y. Process Optimization for Ultrasonic Extraction of Lavonoids and Determination of Antioxidation Effect in Iris lactea Pall.Var. chinensis Koidz. Mod. Agric. Sci. Technol. 2014, 2, 301-303. [CrossRef]

4. Liu, C.X.; Li, Q.S.; Gao, L.Y. Studies on the Determination of Irisquinone A and B in Biological Samples. Chin. Tradit. Herb. Drugs 1998, 29, 533-535.

5. Colin, D.; Lancon, A.; Delmas, D.; Lizard, G.; Abrossinow, J.; Kahn, E.; Jannin, B.; Latruffe, N. Antiproliferative activities of resveratrol and related compounds in human hepatocyte derived HepG2 cells are associated with biochemical cell disturbance revealed by fluorescence analyses. Biochime 2008, 90, 1674-1684. [CrossRef] [PubMed]

6. Zhu, W.; Sun, W.; Yongchun, Y.U. The impact of radiosensitizer irisquinone on lung metastasis in H22-bearing mice. Jiangsu Med. J. 2008, 34, 176-178. [CrossRef]

7. Zhang, F.G.; Li, D.H.; Qi, J.; Liu, C.X. In Vitro Anticancer Effects of Pallasone A and Its Induced Apoptosis on Leukemic K562 Cells. Chin. Pharm. J. 2010, 22, 1716-1719.

8. Fu, L.W.; Li, X.B.; Liang, Y.J.; Feng, H.L.; Zhang, Y.M.; Pang, Q.C. Effect of irisquinone on cytotoxicity to the cancer cells with multidrug resistance and its mechanism. Chin. Pharmacol. Bull. 2001, 17, 234-236. [CrossRef]

9. Zhou, Y.Q.; Bian, X.H. Clinical Study on NPC Radiosensitization of Irrisquinones. Acta Univ. Med. Nanjing 2001, 21, 328-330. [CrossRef]

10. Wang, X.W. Irisquinone: Antineoplastic, radiosensitizer. Drugs Future 1999, 24, 613-617. [CrossRef]

11. Meng, Y.; Qin, M.J.; Qi, B.Q.; Xie, G.Y. Four new C-glycosylflavones from the leaves of Iris lactea Pall. var. chinensis (Fisch.) Koidz. Phytochem. Lett. 2017, 22, 33-38. [CrossRef]

12. Zhou, T.R.; Ge, G.T.; Jia, Y.S.; Hou, M.L.; Wang, W.; Nuo, M.; Ba, D.L.H. The effect advantage natural grassland on mixed grass group of silage quality. Grassl. Prataculture 2015, 27, 19-26. [CrossRef]

13. Wu, X.A.; Zhao, Y.M.; Yu, N.J. Flavone C-glycosides from Trollius ledebouri reichb. J. Asian Nat. Prod. Res. 2006, 8, 541-544. [CrossRef] [PubMed]

14. Chen, D.X.; Lin, S.; Xu, W.; Huang, M.Q.; Chu, J.F.; Xiao, F.; Lin, J.M.; Peng, J. Qualitative and Quantitative Analysis of the Major Constituents in Shexiang Tongxin Dropping Pill by HPLC-Q-TOF-MS/MS and UPLC-QqQ-MS/MS. Molecules 2015, 20, 18597-18619. [CrossRef] [PubMed]

15. Zhou, Y.; Liu, X.; Yang, J.; Han, Q.B.; Song, J.Z.; Li, S.L.; Qiao, C.F.; Ding, L.S.; Xu, H.X. Analysis of caged xanthones from the resin of Garcinia hanburyi using ultra-performance liquid chromatography/electrospray ionization quadrupole time-of-flight tandem mass spectrometry. Anal. Chim. Acta 2008, 629, 104-118. [CrossRef] [PubMed]

16. Konishi, Y.; Kiyota, T.; Draghici, C.; Gao, J.M.; Yeboah, F.; Acoca, S.; Jarussophon, S.; Purisima, E. Molecular Formula Analysis by an MS/MS/MS Technique To Expedite Dereplication of Natural Products. Anal. Chem. 2007, 79, 1187-1197. [CrossRef] [PubMed]

17. He, Y.J.; Li, Z.K.; Wang, W.; Sooranna, S.R.; Shi, Y.T.; Chen, Y.; Wu, C.Q.; Zeng, J.G.; Tang, Q.; Xie, H.Q. Chemical Profiles and Simultaneous Quantification of Aurantii fructus by Use of HPLC-Q-TOF-MS Combined with GC-MS and HPLC Methods. Molecules 2018, 23, 2189. [CrossRef] [PubMed]

18. Xie, G.Y.; Zhu, Y.; Shu, P.; Qin, X.Y.; Wu, G.; Wang, Q.; Qin, M.J. Phenolic metabolite profiles and antioxidants assay of three Iridaceae medicinal plants for traditional Chinese medicine "She-gan" by on-line HPLC-DAD coupled with chemiluminescence (CL) and ESI-Q-TOF-MS/MS. J. Pharm. Biomed. 2014, 98, 40-51. [CrossRef] [PubMed] 
19. Iswaldi, I.; Arráez-Román, D.; Rodríguez-Medina, I.; Beltran-Debon, R.; Joven, J.; Segura-Carretero, A.; Fernandez-Gutierrez, A. Identification of phenolic compounds in aqueous and ethanolic rooibos extracts (Aspalathus linearis) by HPLC-ESI-MS (TOF/IT). Anal. Bioanal. Chem. 2011, 400, 3643-3654. [CrossRef] [PubMed]

20. Sethi, M.L.; Taneja, S.C.; Dhar, K.L.; Atal, C.K. Three isoflavone-glycosides from juniperus macropoda. Phytochemistry 1983, 22, 289-292. [CrossRef]

21. Liu, S.; Yan, J.; Xing, J.; Song, F.; Liu, Z.; Liu, S. Characterization of compounds and potential neuraminidase inhibitors from the n-butanol extract of Compound Indigowoad Root Granule using ultrafiltration and liquid chromatography-tandem mass spectrometry. J. Pharm. Biomed. 2012, 59, 96-101. [CrossRef] [PubMed]

22. Mizuno, T.; Yabuya, T.; Kitajima, J.; Iwashina, T. Identification of novel C-glycosylflavones and their contribution to flower colour of the Dutch iris cultivars. Plant Physiol. Biochem. 2013, 72, 116-124. [CrossRef] [PubMed]

23. Kawase, A.; Yagishita, K. On the Structure of a New C-Glycosyl Flavone, Embinin, Isolated from the Petals of Iris germanica Linnaeous. Agric. Biol. Chem. 1968, 32, 537-538. [CrossRef]

24. Pryakhina, N.I.; Sheichenko, V.I.; Blinova, K.F. Acylated C-glycosides of Iris lactea. Chem. Nat. Compd. 1984, 20, 554-559. [CrossRef]

25. Shen, W.J.; Qin, M.J.; Shu, P.; Zhang, C.F. Two new C-glycosylflavones from the leaves of Iris lactea var. chinensis. Chin. Chem. Lett. 2008, 19, 821-824. [CrossRef]

26. Bandyukova, V.A.; Yugin, V.A. Natural flavonoid C-glycosides. Chem. Nat. Compd. 1981, 17, 1-21. [CrossRef]

27. Wen, L.R.; Zhao, Y.P.; Jiang, Y.M.; Yu, L.M.; Zeng, X.F.; Yang, J.L.; Tian, M.M.; Liu, H.L.; Yang, B. Identification of a flavonoid C-glycoside as potent antioxidant. Free Radic. Biol. Med. 2017, 110, 92-101. [CrossRef] [PubMed]

28. Thao, N.P.; Luyen, B.T.T.; Widowati, W.; Fauziah, N.; Maesaroh, M.; Herlina, T.; Manzoor, Z.; Ali, I.; Koh, Y.S.; Kim, Y.H. Anti-inflammatory Flavonoid C-Glycosides from Piper aduncum Leaves. Planta Med. 2016, 82, 1475-1481. [CrossRef] [PubMed]

29. Chen, Y.G.; Li, P.; Li, P.; Yan, R.; Zhang, X.Q.; Wang, Y.; Zhang, X.T.; Ye, W.C.; Zhang, Q.W. $\alpha$-Glucosidase Inhibitory Effect and Simultaneous Quantification of Three Major Flavonoid Glycosides in Microctis folium. Molecules 2013, 18, 4221-4232. [CrossRef] [PubMed]

30. Neves, A.R.; Correia-Da-Silva, M.; Silva, P.M.A.; Ribeiro, D.; Emília, S.; Bousbaa, H.; Pinto, M. Synthesis of new glycosylated flavonoids with inhibitory activity on cell growth. Molecules 2018, 23, 1093. [CrossRef] [PubMed]

31. Wang, Y.; Chen, M.; Zhang, J.; Zhang, X.L.; Huang, X.J.; Wu, X.; Zhang, Q.W.; Li, Y.L.; Ye, W.C. Flavone $C$-glycosides from the leaves of Lophatherum gracile and their in vitro antiviral activity. Planta Med. 2011, 78, 46-51. [CrossRef] [PubMed]

32. Liang, M.J.; Xu, W.; Zhang, W.D.; Zhang, C.; Liu, R.H.; Shen, Y.H.; Li, H.L.; Wang, X.L.; Wang, X.W.; Pan, Q.Q.; et al. Quantitative LC/MS/MS method and in vivo pharmacokinetic studies of vitexin rhamnoside, a bioactive constituent on cardiovascular system from hawthorn. Biomed. Chromatogr. 2010, 21, 422-429. [CrossRef] [PubMed]

33. Hawas, U.W.; Soliman, G.M.; Abou ElKassem, L.T.; Farrag, A.R.; Mahmoud, K.; León, F. A new flavonoid C-glycoside from Solanum elaeagnifolium with hepatoprotective and curative activities against paracetamol-induced liver injury in mice. Z. Naturforsch. C J. Biosci. 2013, 68, 19-28. [CrossRef]

34. Jung, I.H.; Lee, H.E.; Park, S.J.; Ahn, Y.J.; Kwon, G.Y.; Woo, H.; Lee, S.Y.; Kim, J.S.; Jo, Y.W.; Jang, D.S.; et al. Ameliorating effect of spinosin, a C-glycoside flavonoid, on scopolamine-induced memory impairment in mice. Pharmacol. Biochem. Behav. 2014, 120, 88-94. [CrossRef] [PubMed]

35. Sekar, M. Molecules of Interest-Mangiferin-A Review. Annu. Res. Rev. Biol. 2015, 5, 307-320. [CrossRef]

36. Benard, O.; Chi, Y. Medicinal Properties of Mangiferin, Structural Features, Derivative Synthesis, Pharmacokinetics and Biological Activities. Mini-Rev. Med. Chem. 2015, 15, 582-594. [CrossRef] [PubMed]

37. D’Archivio, A.A.; Maggi, M.A.; Ruggieri, F.; Carlucci, M.; Ferrone, V.; Carlucci, G. Optimisation by response surface methodology of microextraction by packed sorbent of non steroidal anti-inflammatory drugs and ultra-high performance liquid chromatography analysis of dialyzed samples. J. Pharmaceut. Biomed. 2016, 125, 114-121. [CrossRef] 
38. Berger-Brito, I.; Machour, N.; Morin, C.; Portet-Koltalo, F. Experimental Designs for Optimizing Multi-residual Microwave-assisted Extraction and Chromatographic Analysis of Oxygenated (Hydroxylated, Quinones) Metabolites of PAHs in Sediments. Chromatographia 2018, 81, 1401-1412. [CrossRef]

39. D'Archivio, A.A.; Maggi, M.A. Investigation by response surface methodology of the combined effect of $\mathrm{pH}$ and composition of water-methanol mixtures on the stability of curcuminoids. Food Chem. 2017, 219, 414-418. [CrossRef] [PubMed]

40. Ferreira, S.L.C.; Bruns, R.E.; Ferreira, H.S.; Matos, G.D.; David, J.M.; Brandão, G.C.; Silva, E.G.P.D.; Portugal, L.A.; Reis, P.S.D.; Souza, A.S.; et al. Box-behnken design: An alternative for the optimization of analytical methods. Anal. Chim. Acta 2007, 597, 179-186. [CrossRef] [PubMed]

Sample Availability: Samples of the compounds mangiferin, embinin, irislactin C, embinin A, irislactin A and embinin $\mathrm{C}$ are available from the authors.

(C) 2018 by the authors. Licensee MDPI, Basel, Switzerland. This article is an open access article distributed under the terms and conditions of the Creative Commons Attribution (CC BY) license (http:// creativecommons.org/licenses/by/4.0/). 